\title{
Uma proposição metodológica para a precificação de seguro de receita agrícola no Brasil
}

\author{
A methodological proposition on ratemaking for crop revenue \\ insurance in Brazil
}

Cláudio Silveira Brisolara ${ }^{(D)}$, Vitor Augusto Ozaki² (i)

\begin{abstract}
'Federação da Agricultura e Pecuária do Estado de São Paulo (FAESP), São Paulo (SP), Brasil. E-mail: claudiob@faespsenar.com.br 2Programa de Pós-graduação em Economia Aplicada, Escola Superior de Agricultura Luiz de Queiroz, Universidade de São Paulo (USP), Piracicaba (SP), Brasil. E-mail: vitorozaki@usp.br
\end{abstract}

\begin{abstract}
Como citar: Brisolara, C. S., \& Ozaki, V. A. (2022). Uma proposição metodológica para a precificação de seguro de receita agrícola no Brasil. Revista de Economia e Sociologia Rural, 60(2), e235656. https://doi.org/10.1590/18069479.2021 .235656
\end{abstract}

\begin{abstract}
Resumo: Este estudo apresenta formas alternativas de se calcular a taxa de prêmio do seguro de receita, tomando como exemplo o caso da soja em Campo Mourão e Toledo. O seguro de receita garante proteção contra os riscos de preço e produtividade. A taxa é um dos elementos centrais no desenvolvimento de produtos de seguro, razão pela qual o estudo debruçou-se. Duas abordagens foram apresentadas: a univariada e a bivariada. Os resultados mostraram diferenças significativas quando se comparam as metodologias. O seguro de receita situou-se em patamar mais elevado quando comparado ao seguro de produtividade, possivelmente inflacionada pelo efeito do risco de preço.
\end{abstract}

Palavras-chave: seguro de receita, risco, modelagem estatística, seguro agrícola.

\begin{abstract}
This work aimed to study the alternative ways of calculating the revenue insurance premium rate, taking as an example the case of soybeans in Campo Mourão and Toledo. Revenue insurance guarantees protection against price and yield risks. The premium rate is one of the central elements in the development of insurance products. Two approaches were presented: the univariate and the bivariate. The results showed significant differences when comparing the methodologies. Revenue insurance was at a higher level than the yield insurance, possibly inflated by the effect of price risk.
\end{abstract}

Keywords: revenue insurance, risk, statistical modeling, crop insurance.

\section{Introdução}

O agronegócio no Brasil responde por aproximadamente 22\% do PIB, dando importante contribuição na geração de empregos e superávit na balança comercial. A agropecuária possui riscos que dificultam sobremaneira a estabilidade de renda dos produtores rurais, com reflexos potenciais em toda cadeia produtiva. De acordo com Arias et al. (2015), em relatório do Banco Mundial e Embrapa, denominado "Gestão de Riscos Agropecuários no Brasil: caminhos para uma Visão Integrada", há mais de 60 tipos de riscos enfrentados pelo setor, enquanto aquele que apresenta maior criticidade é a seca.

A seca afeta a produção e compromete o retorno ao investimento. Além de ter sua produção comprometida, o produtor pode ter sua situação agravada no momento da venda de seu produto. Preços baixos podem reduzir ainda mais a receita do produtor, levando-o a uma situação de inadimplência junto ao agente financeiro. Nessa situação, descapitalizado e sem acesso ao crédito, o produtor arrisca-se a iniciar a próxima safra com insumos de qualidade inferior, podendo comprometer ainda mais sua frágil situação.

Para evitar essa espiral de inadimplência, o Governo Federal criou o Programa de Subvenção ao Prêmio do Seguro Rural (PSR), o Programa de Garantia da Atividade Agropecuária (PROAGRO) e o Garantia-Safra, políticas instituídas para administrar os riscos climáticos. Dentre eles, o 
PSR é o que conta com maior orçamento e é o mais importante. Em 2019, o orçamento do PSR foi de R $\$ 380$ milhões. Em 2020, está previsto um orçamento de R $\$ 1$ bilhão e, para 2021, o governo estima um valor de $\mathrm{R} \$ 1,5$ bilhão (Brasil, 2020).

O seguro rural é operacionalizado por corretoras, seguradoras e resseguradoras privadas, por meio de produtos que oferecem proteção não apenas contra as intempéries climáticas, mas também contra as oscilações inesperadas da receita. Tradicionalmente, o mercado sempre operou com a modalidade de seguro contra as intempéries climáticas, denominada seguro de custeio ou seguro de produtividade, na qual os principais riscos cobertos na apólice são relacionados ao clima, por exemplo, seca, granizo e geada.

Recentemente, o mercado lançou um novo produto, chamado de seguro de receita ou faturamento. Este seguro foi concebido para viabilizar a transferência dos riscos de preço e/ou produtividade do segurado para a companhia seguradora, por meio de um contrato padronizado conhecido por apólice de seguro.

Para o produtor rural, uma das principais vantagens do seguro de receita é a possibilidade de incluir em um mesmo instrumento a proteção contra riscos climáticos e de quedas no preço. Porém, por ser um produto novo no mercado doméstico, existe pouca literatura envolvendo a precificação dos riscos, um dos principais parâmetros de um contrato de seguro.

Para precificar corretamente os riscos associados a uma operação de seguros, o mercado necessita de dados estatísticos confiáveis e de qualidade e de metodologias adequadas para cada tipo de segmento. Para ter precisão no cálculo das taxas, é necessário um estudo aprofundado do risco de cada evento, o que no presente caso implica a correta estimação das distribuições das variáveis: preço e produtividade.

O objetivo do estudo é propor uma metodologia de cálculo de prêmio de seguro de receita agrícola, buscando sugerir diretrizes para a modelagem univariada da receita e bivariada dos preços e da produtividade. Como forma de aplicar a metodologia proposta, pretende-se utilizar a cultura da soja em municípios selecionados do estado do Paraná.

\section{Modelagem da produtividade, preço e receita agrícola: revisão da literatura}

\subsection{A modelagem da produtividade}

A modelagem das séries temporais de produtividade agrícola foi extensivamente estudada por diversos pesquisadores. Goodwin \& Ker (1998) relatam que a produtividade comumente apresenta assimetria negativa, que reflete o fato de as plantas terem uma restrição biológica que limita o rendimento máximo. Por outro lado, fatores climáticos afetam o ciclo produtivo, gerando baixas produtividades.

A produtividade agrícola é dependente de um processo biológico condicionado por fenômenos meteorológicos. Por essa razão, a abordagem utilizada por Ker \& Goodwin (2000) e Ozaki (2005) de que as produtividades seguem um processo gerador espaço-temporal tem ganhado relevância. Entretanto, segundo Goodwin \& Ker (2002), a maioria dos trabalhos empíricos utiliza um processo gerador temporal como única dimensão para estimar a densidade da produtividade.

A distribuição da produtividade ao longo dos anos foi tratada preponderantemente como seguindo uma distribuição normal. Um dos primeiros estudos envolvendo o desenvolvimento de uma metodologia para calcular as taxas de prêmio para o seguro agrícola pela distribuição normal foi relatado por Botts \& Boles (1958). Modelos de decisão que demandam simulação de faturamento frequentemente apoiavam-se na premissa da normalidade, não só para a variável produtividade, mas também para os preços (Lapan \& Moschini, 1994). 
Alguns estudos recentes têm rejeitado a hipótese da normalidade, entretanto há outros que concluem que ela não pode ser refutada. Nessa direção, o estudo de Just \& Weninger (1999) elege a distribuição normal como uma adequada opção para a modelagem da produtividade. Esses autores citam que os trabalhos que sugeriram assimetria da produtividade agrícola e rejeitaram a normalidade não oferecem consistência.

Visando promover uma reconciliação com os estudos anteriores, Harri et al. (2009) realizaram estudo com produtividades em nível de município, estimando modelos lineares de tendência, polinomiais e autorregressivos. O trabalho levou os autores a concluírem que a suposição $a$ priori de normalidade é razoável em muitos municípios e regiões dos Estados Unidos, mas os resultados dependem do produto agrícola, das condições da respectiva região e do padrão tecnológico corrente, dentre outros fatores.

Outra distribuição paramétrica bastante utilizada para representar a produtividade agrícola é a beta. Exemplos de estudos que utilizaram essa distribuição são os de Badcock \& Hennessy (1996), Hennessy et al. (1997) e Nelson \& Preckel (1989). Esses autores argumentaram haver evidências consistentes de assimetria e curtose nos dados de produtividade, levando-os a optar pela distribuição beta, em razão da sua capacidade de acomodar assimetrias positivas e negativas. Com base nos estudos avaliados, nota-se que séries curtas de produtividade limitam a utilização de algumas metodologias, favorecendo o uso de técnicas paramétricas que podem ser aplicadas a um número menor de observações.

\subsection{A modelagem do preço}

A modelagem dos preços agrícolas no âmbito do seguro de receita também é bem diversificada. Alternativas baseadas nos preços físicos e futuros vêm sendo testadas, bem como preços derivados das negociações de opções de venda sobre futuros do mercado de bolsa.

A variabilidade dos preços é explicada pela combinação da inelasticidade da demanda e choques de oferta determinados pelas variáveis climáticas. Os preços são estado-dependentes, isto é, condicionados pelas condições de mercado e nível de informação dos agentes em determinado momento no tempo.

Pelo modelo de Black-Scholes (BS) pode-se extrair a volatilidade implícita que é a variabilidade dos preços da commodity derivada das variações das cotações das opções (Hull, 2005). A volatilidade implícita vem sendo utilizada para a modelagem do risco de preços, inclusive no contexto do seguro de receita (Turvey, 1992; Ramirez et al., 2005; Coble et al., 2010).

A conveniência de adotar a log-normal e as evidências de estudos sugerindo que os preços apresentam certa assimetria positiva tornaram a log-normalidade padrão nos estudos de modelagem de risco de preço (Goodwin \& Ker, 2002). Do mesmo modo, no âmbito dos estudos de seguro agrícola, a log-normalidade também é utilizada em grande escala (Badcock \& Hennessy, 1996; Coble et al., 2000; Coble et al., 2010).

Um estudo que aprofundou a modelagem de preços por modelos de heterocedasticidade condicional e distribuições mistas foi conduzido por Goodwin et al. (2000). Os resultados empíricos dessa pesquisa refutaram a normalidade e ofereceram suporte à tese da log-normalidade, concluindo que a utilização da distribuição log-normal implica taxas de prêmio mais elevadas do que as calculadas pela normal.

Um aspecto interessante discutido pelos autores refere-se à necessidade de deflacionar os preços. Segundo os pesquisadores, essa discussão emergiu nos debates do programa de cobertura de receita agrícola (CRC - Crop Revenue Coverage), sendo decidido à época utilizar os preços nominais. Mas esse procedimento não é consensual, pois alguns trabalhos na área de seguro utilizam preços deflacionados, a exemplo de: Tew \& Reid (1988) e Wolf et al. (2009). 
Os produtos de seguro de receita pioneiros nos Estados Unidos utilizavam abordagens distintas. O seguro de receita garantida (RA - Revenue Assurance) utilizava o modelo de BS, assumindo que os preços têm distribuição log-normal. O programa de cobertura de receita agrícola (CRC) utilizava preços de comercialização históricos e pressupunha que sua distribuição era normal. O CRC, de acordo com Goodwin et al. (2000), não considerava em sua metodologia a correlação entre preço e produtividade. O plano de proteção de renda (IP - Income Protection) também utiliza séries históricas de preço do mercado físico, mas utiliza uma distribuição não paramétrica.

\subsection{A modelagem da receita bruta}

Embora se avalie os riscos de produtividade e preços por meio das suas densidades, a associação e o estudo da estrutura de dependência dessas variáveis para mensurar adequadamente o risco da receita agrícola são considerados desafiadores. O principal problema da modelagem da receita agrícola está na necessidade de determinar o grau de correlação entre as variáveis, pois elas dificilmente têm comportamentos independentes. Preço e produtividade tendem a ser negativamente correlacionados, mas isso depende do produto agrícola, do grau de integração dos mercados, estoques, aspectos logísticos, ciclo de produção e outras variáveis que significam que a correlação deve ser analisada localmente (Goodwin \& Ker, 2002).

A correlação negativa entre essas variáveis é benéfica ao produtor e à seguradora, pois configura uma espécie de proteção natural contra a redução da receita, uma vez que a redução da produtividade pode ser compensada por uma elevação do preço do produto.

A mensuração do risco de redução da receita é realizada preponderantemente por procedimentos que avaliam a distribuição marginal das variáveis produtividade e preço, levando em conta o grau de correlação entre elas. Se as variáveis advêm de famílias paramétricas comuns, uma função de densidade e probabilidade conjunta pode ser utilizada para gerar sorteios correlacionados por simulação. Contudo, se as variáveis são originárias de diferentes famílias paramétricas, algum outro método de sorteio correlacionado dessas variáveis aleatórias de diferentes distribuições marginais precisa ser utilizado.

Para Goodwin \& Ker (2002), duas abordagens têm se destacado no objetivo de acoplar amostras aleatórias de variáveis correlacionadas, provenientes de distribuições marginais distintas. A primeira abordagem é chamada de combinação linear ponderada, desenvolvida por Johnson \& Tenenbein (1981). Esse método apresenta a restrição de ser paramétrico, exigindo conhecimento a priori das distribuições marginais e do grau de correlação entre as variáveis.

A outra abordagem que vem sendo utilizada e é promissora em termos de mensuração do risco de relações multivariadas é o método de cópulas, proveniente de estudos derivados do mercado financeiro (Umberto, 2011). Uma cópula é uma função $C(\bullet)$ que relaciona as distribuições marginais $\mathrm{F}(\bullet)$ em uma função conjunta de distribuição tal que: $\mathrm{C}\left[\mathrm{F}\left(X_{1}\right), \mathrm{F}\left(X_{2}\right), \ldots \mathrm{F}\left(X_{N}\right)\right]=\mathrm{F}\left(X_{1}, X_{2}, \ldots X_{N}\right)$.

O método utiliza técnicas de aproximação e, portanto, compartilha muitas limitações da abordagem de combinação linear ponderada. As cópulas têm natureza paramétrica e são, assim, suscetíveis a erros de especificação funcional e de aproximação.

Micheleto (2011) utilizou o método de cópulas para calcular o prêmio de seguro de receita bruta de milho no Paraná. Na modelagem da cópula, o autor utilizou uma distribuição não paramétrica para a série de preços e uma distribuição beta para a série de produtividades. O autor defendeu o uso do método de cópulas devido a sua flexibilidade com relação às distribuições marginais, pois permitem que as próprias observações exprimam a forma mais adequada de representação da interdependência. Contudo, a flexibilidade na estimação da cópula não prescinde da definição a priori das formas funcionais das distribuições de probabilidade das variáveis, o que é uma restrição. 
Em outro estudo realizado no Brasil, Adami \& Ozaki (2016) compararam as taxas empíricas com as taxas calculadas por meio de um modelo baseado na normal assimétrica, para a soja em municípios do Oeste do Paraná. O estudo concluiu pela viabilidade do modelo, mas recomendou a realização de trabalhos adicionais, pois os resultados indicaram que em níveis de cobertura mais baixos pode estar ocorrendo subestimação das taxas.

Bielza et al. (2004) acoplaram as distribuições de preço e produtividade utilizando a metodologia de combinação linear ponderada, com o intuito de calcular a taxa de prêmio de um seguro de receita, como política de estabilização da renda de produtores de olivas na Espanha. Os autores assumiram a distribuição beta para a produtividade e uma distribuição mista de normal e log-normal para o preço.

Essas abordagens assumiram que produtividade e preços apresentam distribuições assimétricas diferentes. Entretanto, quando as variáveis são correlacionadas e as distribuições "bem comportadas", a prática mais direta e parcimoniosa é adotar a distribuição normal bivariada para avaliar os riscos (Badcock \& Hennessy, 1996).

A distribuição normal bivariada permite flexibilidade na modelagem de distribuições conjuntas; porém, a limitação dessa metodologia está na pressuposição de que a matriz de correlação contém toda a informação necessária sobre dependência das variáveis (Vedenov, 2008).

\section{Metodologia}

A metodologia apresentada a seguir refere-se a um produto de seguro de receita para a soja que cobre uma determinada proporção $(\gamma)$ da receita bruta média $\left(r_{\mu}\right)$ do empreendimento, chamada de receita garantida $\left(r_{g}\right)$.

Há diferentes formas de determinar a produtividade e o preço base ${ }^{1}$ de garantia que fixam a receita bruta esperada. No presente estudo, optou-se por utilizar a produtividade média histórica municipal de soja, representada no modelo por $y_{\mu}$. O preço base foi determinado a partir da média histórica dos preços de soja $\left(z_{\mu}\right)$ entre os meses de março e maio (período de colheita), do indicador de preços da soja ESALQ/BM\&FBOVESPA, considerando as safras compreendidas entre 2006/07 e 2011/12.

A receita bruta média esperada $\left(r_{\mu}\right)$ é calculada pela multiplicação do preço base $z_{\text {base }}$, em $\mathrm{R} \$$ por saca de 60 quilos, pela produtividade média de soja $y_{\mu}$, em sacas por hectare, conforme a Equação 1:

$r_{\mu}=z_{\text {base }} y_{\mu}$

Considerando que $\gamma$ representa o nível de cobertura do seguro, $a_{s}$ é área total segurada, a receita garantida $r_{g}$ pode ser representada pela Equação 2:

$r_{g}=\gamma r_{\mu} a_{S}$

Como a dimensão da área não implica o cálculo das taxas de prêmio, considerou-se na Equação 2 a área total igual a um hectare, ou seja, $a_{s}=1$. No modelo de seguro descrito, a indenização é devida quando a receita total observada na área segurada $(r)$ for inferior a $r_{g}$, quer seja por baixa produtividade, redução dos preços ou combinação de ambos os eventos.

${ }^{1}$ Optou-se pela nomenclatura de preço base para designar o preço que fixa a garantia de receita e não por preço garantido para facilitar a interpretação, tendo em vista que o seguro de receita não garante qualquer nível de preço, mas o nível de receita, que é determinado por inúmeras combinações das variáveis preço e produtividade. 
Assim, conforme expressa a Equação 3, a indenização ocorre quando $r<r_{g}$, caso contrário, não há indenização a ser paga. O produto de seguro pode ser representado pela Equação 3 , que segue:

$I=\max \left[\left(r_{g}-r\right), 0\right]$

Destaca-se que o cálculo da receita observada $(r)$ deve levar em conta a produção efetivamente colhida na área segurada, multiplicada pelo preço de colheita, conforme metodologia de apuração consignada na apólice de seguro. No modelo proposto, fixou-se como preço efetivo de colheita a média do indicador de preço de soja ESALQ/BM\&FBOVESPA para os meses de março, abril e maio. Os níveis de cobertura simulados variaram de $60 \%$ a $90 \%$, com incrementos de $5 \%$. As simulações e análises realizadas no estudo foram realizadas no software R, versão 3.6.3.

\subsection{Cálculo da taxa de prêmio pela abordagem univariada}

Dada a limitação do número de observações de produtividade e preço da soja, foram simuladas observações adicionais, tal como sugerido em Hennessy et al. (1997). Quando os vetores simulados de produtividade e preço são multiplicados para gerar um novo vetor de receita esperada, automaticamente a estrutura de correlação das variáveis originais é desconsiderada.

Entretanto, devido à restrição imposta pelo comprimento da série de preços, adotou-se esse procedimento na abordagem univariada. Foi gerado o vetor de receita bruta $(R)$ a partir dos vetores simulados com 20.000 observações independentes de produtividade e preço. O vetor resultante com observações geradas de receita bruta passou a ser a variável de interesse para se calcular a probabilidade de perda, entendida como a probabilidade de $R<r_{g}$, para diferentes níveis de cobertura. Desse modo, as taxas de prêmio puro foram calculadas, aplicando-se à Equação 4, reproduzida abaixo:

$T P_{(r, \gamma)}=\frac{p\left(R<r_{g}\right)\left[\gamma r_{\mu}-E\left(R \mid r<r_{g}\right)\right]}{\gamma r_{\mu}}$

A Equação 4 fornece diretamente a taxa de prêmio pura $T P_{(r, \gamma)}$ do seguro de receita, sendo que o subíndice $r$ indica seguro de receita e $r$ equivale ao nível de cobertura escolhido, que varia de $60 \%$ a 90\%. A multiplicação da receita média esperada pelo nível de cobertura resulta na receita garantida, $r_{\mathrm{g}}$. Essa formulação advém da solução proposta por Lawas (2005), para uma série univariada de produtividade, com a diferença de que na Equação 4 o gatilho do seguro é a receita bruta.

Para permitir a comparação das taxas calculadas do seguro de receita com as taxas do seguro de produtividade, a fim de verificar o incremento gerado pelo risco de preço, foram calculadas as taxas para o seguro de produtividade, utilizando as mesmas séries de produtividade $(\boldsymbol{\eta})$. Para tanto, foi empregada a Equação 5:

$T P_{(p, \gamma)}=\frac{p\left(Y<y_{g}\right)\left[\gamma \mu-E\left(Y \mid y<y_{g}\right)\right]}{\gamma \mu}$

A Equação 5 fornece a taxa de prêmio pura $T P_{(p, \gamma)}$ do seguro de produtividade, sendo que $p$ indica seguro de produtividade e $\gamma$ nível de cobertura escolhido para o seguro, variando de $60 \%$ a 90\%. A multiplicação da produtividade média esperada pelo nível de cobertura resulta na produtividade garantida, $y_{g}$. 
Outro ponto importante refere-se à normalização das séries de produtividade. Ao longo dos anos, o progresso tecnológico amplia a produtividade agrícola. Nesse contexto, a produtividade alcançada em 1985 não pode ser comparada com a produtividade de 2005, sendo necessário retirar o efeito do avanço tecnológico que imprime uma tendência determinística de aumento de produtividade às séries. Para o tratamento das séries de produtividade, tanto para a retirada da tendência quanto para correção da heterocedasticidade, foi utilizado o modelo multiplicativo de normalização das séries, sugerido por Goodwin \& Mahul (2004) e descrito na Equação 6:

Produtividadenormalizada $_{t}=y_{2011} \times\left(1+e_{t} / y_{t}\right)$

O método consiste na estimação de equação de produtividade, tendo o ano como variável explicativa. A seguir, calcula-se uma taxa que advém do erro da estimação $\left(e_{t}\right)$ sobre a produtividade estimada $\left(y_{t}\right)$, multiplicada pela produtividade estimada do ano para o qual se quer normalizar a série $\left(y_{2011}\right)$. Desse modo, a tendência decorrente do incremento tecnológico é retirada da série, gerando uma série normalizada de produtividade.

A correção da série de preços é um procedimento não consensual, pois há pesquisadores que a defendem e outros que não. Entretanto, a realidade econômica brasileira é diferente da vivenciada por Estados Unidos e Canadá, onde os trabalhos citados foram desenvolvidos. A alternativa utilizada é a de simplesmente deflacionar a série, para corrigir o valor monetário no tempo, tal como sugerido em Tew \& Reid (1988) e Wolf et al. (2009).

\subsection{Cálculo da taxa de prêmio pela abordagem bivariada}

A abordagem bivariada é levada a efeito para a determinação do risco da receita agrícola pelo uso da distribuição normal bivariada, considerando que as distribuições de preço e produtividade são aproximadas pela normal. Caso necessário, transformações nas variáveis podem ser efetuadas para garantir a aproximação da distribuição da receita bruta pela normal.

Outro modo de analisar o risco da receita é considerar que preços e produtividades exibem distribuições marginais distintas, com assimetria, e implantar um método mais robusto que relacione essas distribuições, permitindo que os desvios sejam não normais.

No presente trabalho, o comportamento das variáveis produtividade e preço permitiu a utilização da primeira abordagem, assumindo-se que as variáveis têm distribuição normal bivariada. Essa distribuição é computacionalmente menos intensiva, matematicamente tratável e sua utilização permite a extração de resultados consistentes, por meio de procedimento parcimonioso.

Segundo Johnson \& Wichern (2007), a distribuição normal exerce um papel fundamental na análise multivariada, pois, embora os dados não tenham um comportamento exatamente normal, a densidade normal é usada com frequência na aproximação da distribuição verdadeira da população. A função de densidade normal multivariada tem a forma apresentada na Equação 7:

$f(x)=\frac{1}{(2 \pi)^{p / 2}|\Sigma|^{1 / 2}} e^{-(x-\mu)^{\prime} \Sigma^{-1}(x-\mu) / 2}$

A densidade normal multivariada é denotada por $N_{p}(\mu, \Sigma)$, formulação análoga à da função de densidade normal univariada. A função de densidade bivariada é o caso mais simples da função multivariada. Seja $x_{1}$ e $x_{2}$ um par aleatório, então a função densidade de probabilidade assume a forma da Equação 8, a seguir: 


$$
f\left(x_{1}, x_{2}\right)=\frac{1}{2 \pi \sqrt{\sigma_{11} \sigma_{22}\left(1-\rho_{12}^{2}\right)}} \times \exp \left\{-\frac{1}{2\left(1-\rho_{12}^{2}\right)}\left[\left(\frac{x_{1}-\mu_{1}}{\sqrt{\sigma_{11}}}\right)^{2}+\left(\frac{x_{2}-\mu_{2}}{\sqrt{\sigma_{22}}}\right)^{2}-2 \rho_{12}\left(\frac{x_{1}-\mu_{1}}{\sqrt{\sigma_{11}}}\right)\left(\frac{x_{2}-\mu_{2}}{\sqrt{\sigma_{22}}}\right)\right]\right\}
$$

Para calcular as probabilidades é preciso obter a densidade condicional da distribuição normal bivariada. Assim, a densidade condicional de $X_{1}$, dado que $x_{2}=x_{2}$, para uma distribuição bivariada, é definida por (Equação 9):

$$
f\left(x_{1} \mid x_{2}\right)=\frac{1}{\sqrt{2 \pi} \sqrt{\sigma_{11}\left(1-\rho_{12}^{2}\right)}} \exp -\left[x_{1}-\mu_{1}-\left(\frac{\sigma_{12}}{\sigma_{22}}\right)\left(x_{2}-\mu_{2}\right)\right]^{2} /\left[2 \sigma_{11}\left(1-\rho_{12}^{2}\right)\right]
$$

A normalidade foi avaliada pelo teste de Jarque-Bera e pela análise gráfica, sobrepondo à distribuição de frequência dos dados com uma curva de densidade estimada com o Kernel como ponderador e com a curva característica da normal.

Para viabilizar a análise multivariada e contornar o problema da periodicidade e extensão da série de dados, nas simulações pela normal bivariada também foram geradas 20.000 observações de produtividade e preço, mas com a incorporação da estrutura de dependência das variáveis, por meio da matriz de variância e covariância.

Após a obtenção dos vetores correlacionados de produtividade $(y)$ e preço (z), para cada município, estes foram multiplicados para calcular a receita bruta $(r)$. Em seguida, com base nos níveis de cobertura, calculou-se a probabilidade de perda $\left(R<r_{g}\right)$ e a esperança de perda $\left[\gamma r_{\mu}-E\left(R \mid r<r_{g}\right)\right]$, para se calcular o prêmio de seguro $T P_{(r, \gamma)}$, lembrando que os subscritos $r$ e $\gamma$ indicam, respectivamente, seguro de receita e o nível de cobertura do prêmio calculado.

A probabilidade de perda $\left(R<r_{g}\right)$ está condicionada pelos respectivos valores de $z$ e que definem $r$, considerando que $r_{g}$ é definida pela multiplicação de $z$ e $y$. A probabilidade é, desse modo, condicionada: $p^{*}=\operatorname{prob}\left(Z<z ; Y y \mid z y<r_{g}\right)$. A equação que expressa a forma de cálculo adotada é a que segue:

$T P_{(r, \gamma)}=\frac{p\left(Z<z ; Y y \mid z y<r_{g}\right) \times\left[\gamma r_{\mu}-E\left(Z Y \mid z y<r_{g}\right)\right]}{\gamma r_{\mu}}$

Desse modo, a Equação 10 é utilizada para o cálculo da taxa de prêmio de seguro de receita $\left[T_{(r, \gamma)}\right]$, considerando a distribuição conjunta de probabilidade de preço e produtividade.

\section{Descrição dos dados}

Para ilustrar a aplicação da metodologia proposta, utilizaram-se as séries de produtividade, em quilogramas por hectare, dos municípios de Toledo e Campo Mourão, obtidas no Instituto Paranaense de Desenvolvimento Econômico e Social (2018), para o período de 1980 a 2011.

As séries têm periodicidade anual e contam com 32 observações de cada município. Para a análise de correlação, foram também utilizadas séries de produtividade média de soja do estado do Paraná e do Brasil. O rendimento médio paranaense foi obtido de Instituto Paranaense de Desenvolvimento Econômico e Social (2018) e o brasileiro de Instituto Brasileiro de Geografia e Estatística (2018), para o mesmo período.

Para as simulações, cálculo do risco de preço e taxa de prêmio, utilizou-se o indicador de preço de soja ESALQ/BM\&FBOVESPA. Essa série de preços é de grão comercializado na condição 
de "transferido"" para armazéns ou silos portuários no corredor de exportação do Porto de Paranaguá (Centro de Estudos Avançado em Economia Aplicada, 2018).

Ademais, deflacionou-se a série de preços do indicador de soja e, em seguida, avaliaram-se o comportamento dos dados e a necessidade de correções. Para deflacionar as séries de preços, optou-se por utilizar o Índice Geral de Preços Disponibilidade Interna - IGP-DI ${ }^{3}$, da Fundação Getúlio Vargas, por refletir preponderantemente a inflação no atacado, nível de mercado que abrange o indicador de preço de soja ESALQ/BM\&FBOVESPA.

\section{Resultados e discussão}

\subsection{Análise das séries de produtividade}

Inicialmente, cabe observar que as produtividades históricas de Campo Mourão e Toledo apresentaram tendência acentuada, comportamento característico de séries que expressam ganho de produtividade pelo uso de tecnologia. Portanto, antes de aprofundar a análise foi preciso retirar a tendência das séries, pois não se deseja modelar o progresso tecnológico, mas a variação de produtividade oriunda de fenômenos climáticos e biológicos.

A Figura 1 mostra que a tendência característica das séries originais foi retirada, pois as séries corrigidas não apresentam inclinação, ao contrário da série original. É também relevante notar que as séries corrigidas conservam a variabilidade característica das séries originais, elemento fundamental para a mensuração do risco de redução de produtividade.

Após a correção das séries e a confirmação de que a tendência foi extraída, procederamse às análises para avaliar as distribuições de probabilidade das variáveis e a existência de evidências que rejeitassem a normalidade.

Conforme sugestão de Upadhyay \& Smith (2005), foram empregados os testes de AndersonDarling e Shapiro-Wilk para avaliar a normalidade de séries curtas de produtividade. Os resultados dos testes, apresentados no Quadro 1, não permitem que se rejeite a hipótese nula e, por sua vez, a pressuposição de normalidade.
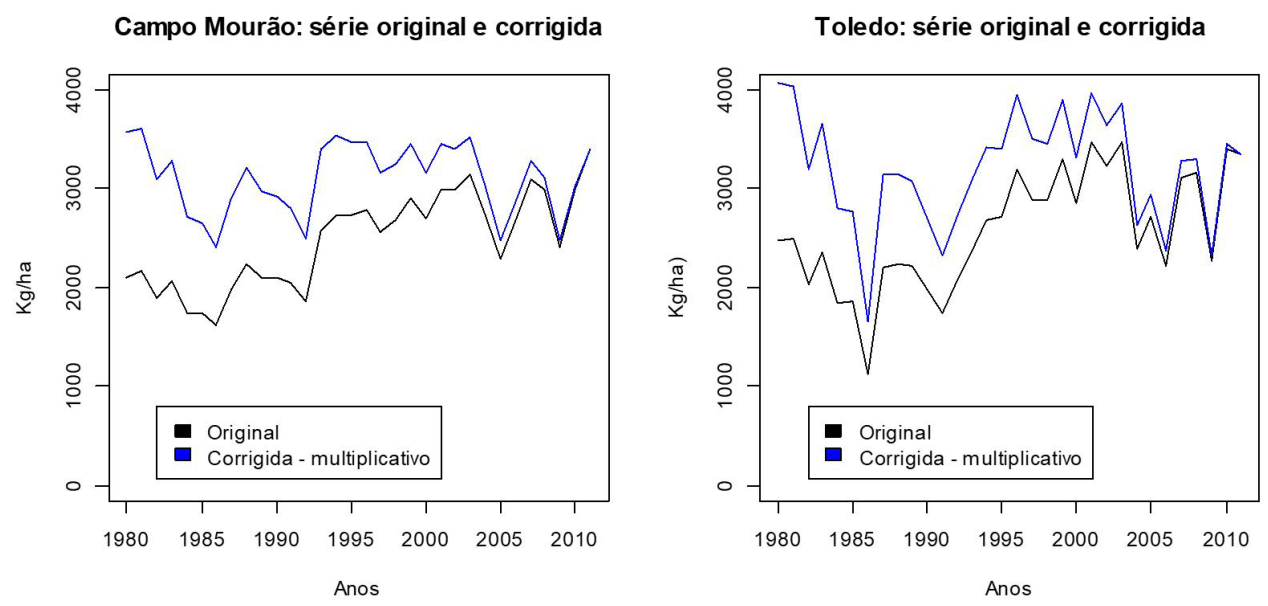

Figura 1. Séries originais e corrigidas de produtividade em Campo Mourão e Toledo. Fonte: resultados da pesquisa.

\footnotetext{
2 Significa que a soja está em silo ou armazém portuário que efetua carregamento de navios para exportação.

${ }^{3}$ Série obtida em Fundação Getúlio Vargas (2018), por meio do seguinte endereço: http://portalibre.fgv.br/.
} 
Quadro 1. Teste de normalidade das produtividades de soja de Campo Mourão e Toledo

\begin{tabular}{|c|c|c|}
\hline \multicolumn{3}{|c|}{ Campo Mourão } \\
Anderson-Darling (AD) \\
\hline Estatística & 0,62 & 0,33 \\
\hline Valor- $p$ & 0,10 & 0,51 \\
\hline \multicolumn{3}{|c|}{ Shapiro-Wilk } \\
\hline Estatística & 0,93 & 0,96 \\
\hline Valor- $p$ & 0,05 & 0,29 \\
\hline
\end{tabular}

Fonte: resultados da pesquisa

As distribuições das produtividades em Campo Mourão e Toledo, graficamente, sugerem um relativo distanciamento da distribuição normal. Comparando-se os dois municípios, na Figura 2, Toledo aproxima-se mais da normal que a distribuição da produtividade de Campo Mourão.
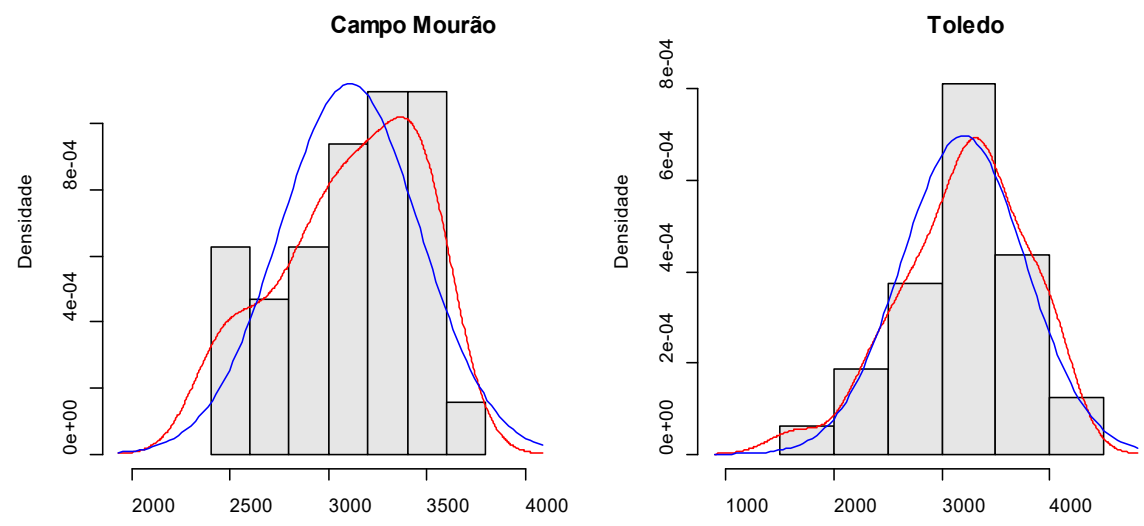

Figura 2. Histograma, densidade normal e não paramétrica das produtividades de soja em Campo Mourão e Toledo. Fonte: resultados da pesquisa.

Considerando que as análises apresentadas não rejeitam a hipótese de normalidade, utilizarse-á a distribuição normal para representar o comportamento da distribuição dos dados de produtividade.

\subsection{Análise da série de preços}

Enquanto a produtividade tem um comportamento mais previsível, com tendência estacionária, os preços possuem uma dinâmica mais difusa, influenciada pela integração ao mercado internacional, câmbio, exportações, oferta e demanda internacional, dentre outros fatores.

Para a modelagem do risco de preço, o ideal seria contar com bases de preços municipais confiáveis, mas não se dispõe de tais informações. No caso do Paraná, a alternativa mais razoável foi modelar o risco utilizando como base no Porto de Paranaguá, por intermédio do indicador de preço de soja ESALQ/BM\&FBOVESPA.

Normalmente, os produtos de seguro fixam o preço base ou preço de garantia na média de preços futuros para a época de colheita. Neste estudo, optou-se por utilizar preços médios de referência para o período de colheita. Na Figura 3 são apresentadas as séries, nominal e deflacionada, do indicador de preço de soja ESALQ/BM\&FBOVESPA. 
É possível perceber que a deflação dos preços, além de permitir a comparação das cotações em termos reais, em valores de junho de 2012, funciona como um procedimento não linear de suavização da tendência. A linha traçada na Figura 3 representa o preço médio da série deflacionada, equivalente a $\mathrm{R} \$ 52,25$ por saca.

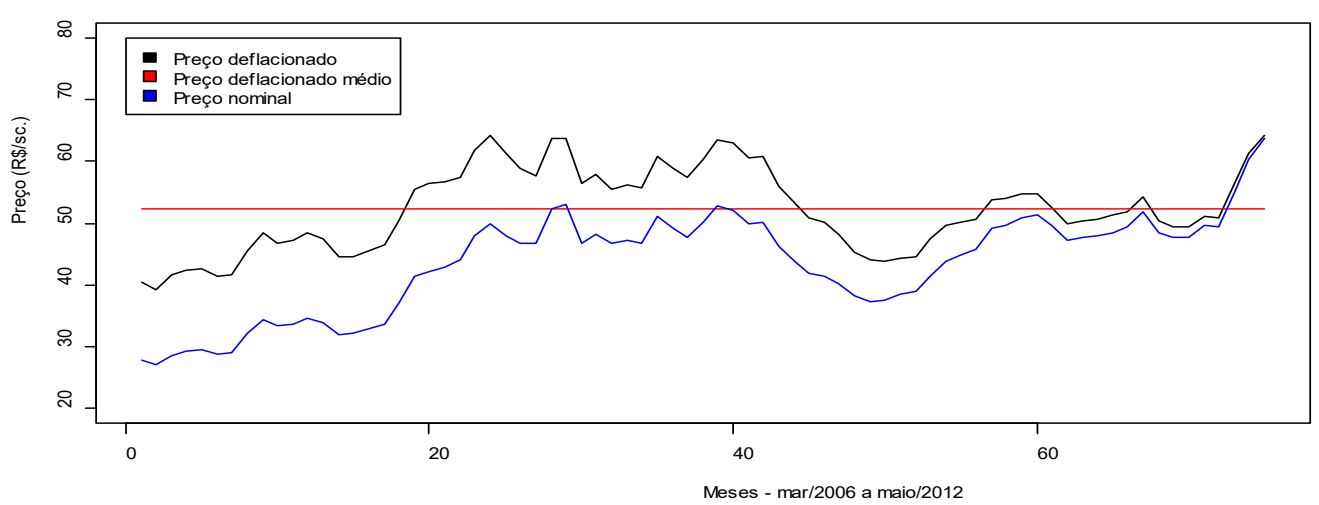

Figura 3. Preços médios mensais nominais e deflacionados do indicador de preço da soja ESALQ/ BM\&FBOVESPA. Fonte: Centro de Estudos Avançado em Economia Aplicada (2018)

Em seguida, analisou-se a série de preços deflacionada. Na Figura 4 pode-se visualizar as curvas normal e não paramétrica sobrepostas ao histograma de frequência da série de preços deflacionada (gráfico a). Na mesma figura, é apresentado o gráfico Quantil-Quantil (b).

A análise do histograma, em conjunto com o gráfico Quantil-Quantil, evidencia que, a despeito da maior disparidade nas caudas, o comportamento dos preços não se distancia acentuadamente da distribuição normal.

A normalidade da distribuição dos preços foi examinada também pelos testes de AndersonDarling e Shapiro-Wilk. Os resultados dos testes, no Quadro 2, indicam a não rejeição da hipótese nula de normalidade.
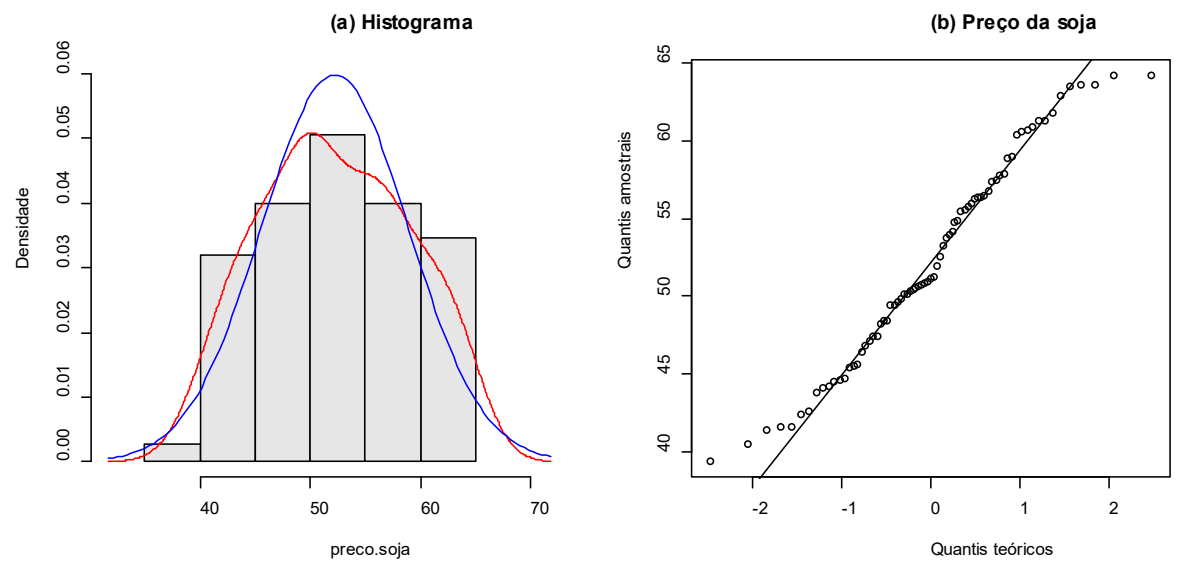

Figura 4. Histograma (a) e gráfico Quantil-Quantil (b) dos preços médios mensais deflacionados do indicador de preço de soja ESALQ/BM\&FBOVESPA. Fonte: resultados da pesquisa.

Portanto, concluiu-se pela viabilidade metodológica de aproximar a distribuição da série deflacionada do indicador de preço da soja ESALQ/BM\&FBOVESPA pela distribuição normal. 
Em seguida, extraiu-se uma subamostra da série de preços, com o intuito de obter a média e o desvio-padrão dos preços na época de colheita, no período de 2008 a 2012, equivalentes às últimas cinco safras.

Quadro 2. Teste de normalidade para o preço da soja

\begin{tabular}{|c|c|}
\hline $\begin{array}{c}\text { Teste de normalidade } \\
\text { Estatística }\end{array}$ & Preço deflacionado \\
\hline Valor- $p$ & 0,49 \\
\hline \multicolumn{2}{|c|}{ Shapiro-Wilk (S-W) } \\
\hline Estatística & 0,21 \\
\hline Valor- $p$ & 0,97 \\
\hline
\end{tabular}

Fonte: resultados da pesquisa

\subsection{A correlação de produtividade e preço}

A utilização de modelos bivariados exige a identificação da estrutura de dependência entre a produtividade e o preço. Essa necessidade advém do modelo de simulação que requer a especificação da matriz de variância e covariância $(\Sigma)$ para viabilizar o sorteio correlacionado de preços e produtividades durante as simulações.

Foram calculados os coeficientes de correlação linear de Pearson. Os resultados apontam para coeficientes de correlação baixos, mas positivos, entre produtividade e preço. É importante destacar que o teste de significância dos coeficientes não permite que se aceitem esses valores como significantes nem mesmo a $10 \%$.

Quadro 3. Correlação linear das produtividades em Campo Mourão e Toledo com o preço médio na colheita (ESALQ/BM\&FBOVESPA), de 2005 a 2011

\begin{tabular}{|c|c|c|c|}
\hline Matriz de Correlação & Prod. C. Mourão & & \\
\hline Prod. Campo Mourão & 1,00 & 1,00 & \\
\hline Prod. Toledo & $0,77^{\star \star}$ & 0,21 & 1,00 \\
\hline Preço na Colheita & 0,17 & Prod. Toledo & \\
\hline
\end{tabular}

Fonte: resultados da pesquisa. Nota: ${ }^{*}{ }^{* \star},{ }^{* * \star}$, denota significância a $1 \%, 5 \%$ e $10 \%$, respectivamente.

Tendo em vista que as séries analisadas são curtas, decidiu-se utilizar uma série mais longa de preços, de 1996 a 2011, em nível estadual, para ampliar a análise e recalcular as estatísticas. O resultado esperado de correlação linear negativa foi observado apenas em Toledo, quando se utilizou a série de preços mais longa. Entretanto, o parâmetro estimado também não apresentou significância estatística, considerando que o $t$ calculado foi de $-0,94$ e o valor- $p$ foi de 0,36 , de modo que o intervalo de confiança inclui o zero. Nas demais situações, encontrouse correlação linear positiva, com parâmetros não significantes.

Como esses resultados não trouxeram informações adicionais, decidiu-se utilizar a correlação apresentada no Quadro 3, ainda que as estimativas não sejam significantes e tenham sinal distinto do esperado.

\subsection{Modelagem da taxa de prêmio pela abordagem univariada}

O primeiro modelo de precificação de taxa de prêmio visou representar o faturamento bruto a partir da multiplicação dos vetores simulados de produtividade e preço de soja. Com isso, 
o risco de redução do faturamento e o cálculo da taxa de prêmio foram calculados de modo univariado, considerando exclusivamente o vetor de receita bruta. Conforme se mencionou, esse procedimento não considera a estrutura de dependência entre as variáveis, pois as simulações não são correlacionadas.

Antes de discutir os valores calculados, é importante frisar que as taxas puras diferem das taxas comerciais ofertadas pelas seguradoras. A taxa pura reflete exclusivamente o risco do negócio, enquanto a taxa comercial é determinada pela primeira acrescida do carregamento de despesas administrativas, comerciais e da margem de lucro visada pela companhia seguradora. Portanto, as taxas puras calculadas não podem ser comparadas diretamente com as taxas comerciais das seguradoras, pois, para compará-las, é preciso deduzir as taxas de carregamento embutidas nas taxas comerciais, ou acrescentá-las às taxas puras calculadas.

No Quadro 4 apresentam-se as taxas puras calculadas para o seguro de receita, com níveis de cobertura de $60 \%$ a $90 \%$. De modo geral, a taxa de prêmio calculada para Toledo é mais elevada que a de Campo Mourão, para todos os níveis de cobertura.

Quadro 4. Resumo das taxas calculadas para o seguro de receita bruta pela abordagem univariada

\begin{tabular}{|c|c|c|c|c|}
\hline \multirow{2}{*}{$\begin{array}{l}\text { Nível de } \\
\text { Cobertura } \\
\text { (NC - \%) }\end{array}$} & \multicolumn{2}{|c|}{ Campo Mourão } & \multicolumn{2}{|c|}{ Toledo } \\
\hline & $\begin{array}{l}\text { Receita } \\
\text { garantida } \\
\text { (R\$/ha) }\end{array}$ & $\begin{array}{c}\text { Taxa pura } \\
(\%)\end{array}$ & $\begin{array}{c}\text { Receita } \\
\text { garantida } \\
\text { (R\$/ha) }\end{array}$ & $\begin{array}{c}\text { Taxa pura } \\
(\%)\end{array}$ \\
\hline $60 \%$ & $1.714,12$ & 0,08 & $1.767,64$ & 0,44 \\
\hline $65 \%$ & $1.856,96$ & 0,16 & $1.914,94$ & 0,71 \\
\hline $70 \%$ & $1.999,80$ & 0,34 & $2.062,24$ & 1,14 \\
\hline $75 \%$ & $2.142,64$ & 0,66 & $2.209,55$ & 1,74 \\
\hline $80 \%$ & $2.285,49$ & 1,17 & $2.356,85$ & 2,56 \\
\hline $85 \%$ & $2.428,33$ & 1,98 & $2.504,15$ & 3,62 \\
\hline $90 \%$ & $2.571,17$ & 3,09 & $2.651,46$ & 4,97 \\
\hline
\end{tabular}

Fonte: resultados da pesquisa

Enquanto a taxa de prêmio pura de Campo Mourão inicia com 0,08\% e termina com 3,09\% nos níveis de cobertura de $60 \%$ e $90 \%$, respectivamente, as taxas de Toledo variaram, no mesmo intervalo, de $0,44 \%$ a 4,97\%. As taxas de Toledo são proporcionalmente maiores do que as taxas de Campo Mourão nos níveis de cobertura mais baixos. Com 60\% de NC, a taxa de Toledo representa 5,5 vezes a taxa de Campo Mourão, ao passo que, com NC de 90\%, essa relação é de 1,61 .

Levando em consideração que o seguro de receita pode ser interpretado como um seguro de produtividade acrescido do seguro de preço, é relevante comparar as taxas dessa modalidade de seguro com as taxas do seguro de produtividade, pois isso permite avaliar em quanto o componente preço aumenta a taxa do seguro de produtividade.

Para analisar as taxas calculadas para o seguro de receita e de produtividade é apresentado - Quadro 5, contendo os incrementos líquidos nas taxas em termos absolutos e porcentuais. A diferença absoluta - que exprime o risco de preço - foi obtida pela subtração da taxa do seguro de produtividade da taxa do seguro de receita, enquanto a porcentual resulta da divisão da diferença absoluta pela taxa do seguro de receita, multiplicada por 100.

Em níveis de cobertura mais baixos, a taxa do seguro de receita é bem mais elevada que a taxa do seguro de produtividade, devido à dominância do risco de preço. Na medida em que o nível de cobertura aumenta, a diferença entre as taxas reduz-se em termos relativos. 
Campo Mourão tem risco agrícola menor e por essa razão a proporção do risco de preço na composição da taxa do seguro de receita é sempre maior que em Toledo. Em níveis de cobertura de $60 \%$ e $65 \%$, por exemplo, a taxa de seguro de receita em Campo Mourão é composta exclusivamente pelo risco de preço. E, com NC de $90 \%$, a proporção do risco de preço diminui para 58\%; portanto, nesse município, a maior fonte de risco é o preço.

Quadro 5. Proporção do risco de preço na taxa do seguro de receita e diferenças entre as taxas do seguro de receita e produtividade

\begin{tabular}{|c|c|c|c|c|c|c|}
\hline \multirow[b]{2}{*}{$\begin{array}{c}\text { Nível de } \\
\text { Cobertura } \\
(\%)\end{array}$} & \multicolumn{3}{|c|}{ Campo Mourão } & \multicolumn{3}{|c|}{ Toledo } \\
\hline & $\begin{array}{c}\text { Diferença } \\
\text { absoluta }\end{array}$ & $\begin{array}{c}\text { Diferença } \\
\text { porcentual } \\
(\%)\end{array}$ & $\begin{array}{c}\text { Proporção } \\
\text { do risco de } \\
\text { preço }(\%)\end{array}$ & $\begin{array}{c}\text { Diferença } \\
\text { absoluta }\end{array}$ & $\begin{array}{c}\text { Diferença } \\
\text { porcentual } \\
(\%)\end{array}$ & $\begin{array}{c}\text { Proporção } \\
\text { do risco de } \\
\text { preço (\%) }\end{array}$ \\
\hline $60 \%$ & 0,08 & - & $100 \%$ & 0,30 & $222 \%$ & $69 \%$ \\
\hline $65 \%$ & 0,16 & $12.282 \%$ & $99 \%$ & 0,43 & $154 \%$ & $61 \%$ \\
\hline $70 \%$ & 0,32 & $1.798 \%$ & $95 \%$ & 0,62 & $117 \%$ & $54 \%$ \\
\hline $75 \%$ & 0,58 & $778 \%$ & $89 \%$ & 0,80 & $86 \%$ & $46 \%$ \\
\hline $80 \%$ & 0,95 & $426 \%$ & $81 \%$ & 1,02 & $66 \%$ & $40 \%$ \\
\hline $85 \%$ & 1,39 & $238 \%$ & $70 \%$ & 1,20 & $49 \%$ & $33 \%$ \\
\hline $90 \%$ & 1,78 & $135 \%$ & $58 \%$ & 1,30 & $35 \%$ & $26 \%$ \\
\hline
\end{tabular}

Fonte: resultados da pesquisa

Pode-se notar que o caso de Toledo é diferente. Nos níveis de cobertura de $60 \%$ e $65 \%$, a proporção do risco de preço na taxa do seguro de receita é $69 \%$ e $61 \%$, respectivamente, enquanto se reduz a $26 \%$ no nível de cobertura de $90 \%$.

Essa proporção diferenciada do risco de preço na taxa do seguro de receita explica por que, em Campo Mourão, essa taxa é superior à taxa do seguro de produtividade em 135\%, com nível de cobertura de 90\%, enquanto é de apenas 35\% em Toledo.

\subsection{Modelagem da taxa de prêmio pela abordagem bivariada}

A precificação das taxas de seguro pela abordagem da normal bivariada incorpora a estrutura de correlação das variáveis produtividade e preço, de modo que as simulações são geradas com essa restrição. Apesar da não significância das estimativas de correlação, decidiu-se utilizar os coeficientes de correlação calculados, apresentados no Quadro 6.

Desse modo, passou-se a analisar as distribuições de produtividade e preço de soja por meio da distribuição normal bivariada, $N_{2}(\mu, \Sigma)$, levando em conta as estatísticas estimadas para Campo Mourão e Toledo.

Quadro 6. Resumo das estatísticas utilizadas no cálculo das taxas de prêmio pela abordagem bivariada

\begin{tabular}{|c|c|c|}
\hline Descrição da distribuição & Campo Mourão & Toledo \\
\hline Médias $[\mu]$ & $\mu^{\prime}=[3108,33 ; 55,07]$ & $\mu^{\prime}=[3200,26 ; 55,07]$ \\
\hline $\begin{array}{c}\text { Matriz de variância e } \\
\text { covariância }[\Sigma]\end{array}$ & $\Sigma=\left[\begin{array}{cc}158.002,80 & 591,71 \\
591,71 & 74,63\end{array}\right]$ & $\Sigma=\left[\begin{array}{cc|}245.291,62 & 896,37 \\
896,37 & 74,63\end{array}\right]$ \\
\hline Correlação linear & 0,17 & 0,21 \\
\hline
\end{tabular}

Fonte: resultados da pesquisa 
Para viabilizar a análise multivariada foram geradas 20.000 observações correlacionadas de produtividade e preço. Após a obtenção dos vetores correlacionados para cada município, eles foram multiplicados para construir o vetor de receita bruta $(r)$. Em seguida, com base nos níveis de cobertura, obteve-se a probabilidade de perda $\left(R<r_{g}\right)$ e a esperança da perda $\left[\gamma r_{\mu}-E\left(R \mid r<r_{g}\right)\right]$, para calcular a taxa de prêmio do seguro $T P_{(r, \gamma)}$.

O Quadro 7 exibe a taxa de prêmio pura do seguro de receita bruta pela abordagem bivariada para Campo Mourão, a taxa calculada pela abordagem univariada e a taxa de prêmio para o seguro de produtividade.

Quadro 7. Comparativo das taxas de seguro de produtividade e de receita bruta pelas abordagens univariada e bivariada para Campo Mourão

\begin{tabular}{|c|c|c|c|c|c|}
\hline NC & $\begin{array}{l}\text { Produtividade } \\
\text { garantida } \\
\text { (kg/ha) }\end{array}$ & $\begin{array}{c}\text { Taxa pura seg. } \\
\text { de produtiv. } \\
(\%)\end{array}$ & $\begin{array}{l}\text { Receita } \\
\text { garantida } \\
\text { (R\$/ha) }\end{array}$ & $\begin{array}{l}\text { Taxa pura seg. } \\
\text { de receita } \\
\text { univariada (\%) }\end{array}$ & $\begin{array}{c}\text { Taxa pura seg } \\
\text { de receita } \\
\text { bivariada (\%) }\end{array}$ \\
\hline $60 \%$ & $1.865,52$ & 0,00 & $1.714,12$ & 0,08 & 0,04 \\
\hline $65 \%$ & $2.020,98$ & 0,00 & $1.856,96$ & 0,16 & 0,12 \\
\hline $70 \%$ & $2.176,44$ & 0,02 & $1.999,80$ & 0,34 & 0,32 \\
\hline $75 \%$ & $2.331,90$ & 0,08 & $2.142,64$ & 0,66 & 0,70 \\
\hline $80 \%$ & $2.487,36$ & 0,22 & $2.285,49$ & 1,17 & 1,38 \\
\hline $85 \%$ & $2.642,82$ & 0,58 & $2.428,33$ & 1,98 & 2,39 \\
\hline $90 \%$ & $2.798,28$ & 1,31 & $2.571,17$ & 3,09 & 3,78 \\
\hline
\end{tabular}

Fonte: resultados da pesquisa

É possível perceber no Quadro 7 que, até o nível de cobertura de 75\%, praticamente inexistem diferenças entre as taxas de prêmio calculadas pelas abordagens univariada e bivariada. A partir desse nível de cobertura, as taxas calculadas pela abordagem bivariada começam a se distanciar das estimadas pela univariada. As diferenças são crescentes, de forma que a taxa bivariada é superior à univariada em 18\%,21\% e 22\%, considerando os níveis de cobertura de $80 \%, 85 \%$ e $90 \%$, respectivamente.

Levando em consideração que o modelo bivariado assumiu coeficiente de correlação positivo entre produtividade e preço, os riscos dessas variáveis não são compensáveis. Com isso, esperava-se taxas de prêmio mais elevadas do que as obtidas pela abordagem univariada. Entretanto, as taxas superiores do modelo bivariado só são observáveis em Campo Mourão a partir do nível de cobertura de $75 \%$.

Por outro lado, ao se analisar os resultados do município de Toledo, que apresenta maior risco, conforme já demonstrado, as conclusões têm de ser mais cautelosas. De acordo com o Quadro 8, embora as taxas de prêmio da abordagem univariada sejam superiores às calculadas pela bivariada para os níveis de cobertura de $60 \%$ e $65 \%$, com nível de cobertura de $70 \%$ a taxa de prêmio pela abordagem bivariada $(1,23 \%)$ já é superior à univariada $(1,14 \%)$ em $8 \%$.

Quadro 8. Comparativo das taxas de seguro de produtividade e de receita bruta pelas abordagens univariada e bivariada para Toledo

\begin{tabular}{|c|c|c|c|c|c|}
\hline NC & $\begin{array}{c}\text { Produtividade } \\
\text { garantida } \\
\text { (kg/ha) }\end{array}$ & $\begin{array}{l}\text { Taxa pura seg. } \\
\text { de produt. }(\%)\end{array}$ & $\begin{array}{l}\text { Receita } \\
\text { garantida } \\
\text { (R\$/ha) }\end{array}$ & $\begin{array}{l}\text { Taxa pura seg. } \\
\text { de receita } \\
\text { ( } \% \text { - univ.) }\end{array}$ & $\begin{array}{c}\text { Taxa pura seg. } \\
\text { receita } \\
\text { (\% - biv.) }\end{array}$ \\
\hline $60 \%$ & $1.923,81$ & 0,14 & $1.767,64$ & 0,44 & 0,34 \\
\hline $65 \%$ & $2.084,13$ & 0,28 & $1.914,94$ & 0,71 & 0,67 \\
\hline $70 \%$ & $2.244,45$ & 0,53 & $2.062,24$ & 1,14 & 1,23 \\
\hline
\end{tabular}

Fonte: resultados da pesquisa 
Quadro 8. Continuação...

\begin{tabular}{|c|c|c|c|c|c|}
\hline NC & $\begin{array}{l}\text { Produtividade } \\
\text { garantida } \\
\text { (kg/ha) }\end{array}$ & $\begin{array}{l}\text { Taxa pura seg. } \\
\text { de produt. (\%) }\end{array}$ & $\begin{array}{l}\text { Receita } \\
\text { garantida } \\
\text { (R\$/ha) }\end{array}$ & $\begin{array}{l}\text { Taxa pura seg. } \\
\text { de receita } \\
\text { (\% - univ.) }\end{array}$ & $\begin{array}{l}\text { Taxa pura seg. } \\
\text { receita } \\
\text { (\% - biv.) }\end{array}$ \\
\hline $75 \%$ & $2.404,77$ & 0,94 & $2.209,55$ & 1,74 & 2,06 \\
\hline $80 \%$ & $2.565,09$ & 1,54 & $2.356,85$ & 2,56 & 3,16 \\
\hline $85 \%$ & $2.725,40$ & 2,42 & $2.504,15$ & 3,62 & 4,54 \\
\hline $90 \%$ & $2.885,72$ & 3,68 & $2.651,46$ & 4,97 & 6,20 \\
\hline
\end{tabular}

Fonte: resultados da pesquisa

No caso de Toledo, a taxa de prêmio bivariada torna-se superior à taxa univariada em nível de cobertura mais baixo do que em Campo Mourão, fazendo com que a magnitude da diferença das taxas seja maior. Tomando, novamente, os níveis de cobertura de $80 \%, 85 \%$ e $90 \%$, as taxas calculadas pela abordagem bivariada são superiores às taxas do modelo univariado em 23\%, 25\% e 25\%, respectivamente. Portanto, ao contrário de Campo Mourão, no nível de cobertura de $70 \%$, há uma considerável diferença de taxa de prêmio, razão pela qual a escolha da metodologia de apreçamento da taxa é relevante sob o ângulo atuarial.

O Quadro 9 expõe as diferenças de taxas em termos absolutos e porcentuais, assim como a proporção do risco de preço na composição da taxa de prêmio do seguro de receita. Tal como observado na primeira abordagem, a metodologia bivariada também determina uma maior participação do risco de preço na composição da taxa de prêmio do seguro de receita. Contudo, tanto em Campo Mourão quanto em Toledo, a participação do risco de preço é declinante.

No caso de Campo Mourão, no nível de cobertura de 60\%, o risco de preço é responsável por $100 \%$ da composição da taxa de prêmio do seguro de receita. Contudo, nesse respectivo nível de cobertura, o risco de preço responde por 59\% da taxa de prêmio em Toledo.

Quadro 9. Proporção do risco de preço na taxa de prêmio do seguro de receita e as diferenças entre as taxas do seguro de receita pela abordagem bivariada e de produtividade

\begin{tabular}{|c|c|c|c|c|c|c|}
\hline \multirow{2}{*}{$\begin{array}{c}\text { Nível de } \\
\text { Cobertura } \\
(\%)\end{array}$} & \multicolumn{3}{|c|}{ Campo Mourão } & \multicolumn{3}{|c|}{ Toledo } \\
\hline & $\begin{array}{c}\text { Diferença } \\
\text { absoluta }\end{array}$ & $\begin{array}{c}\text { Diferença } \\
\text { porcentual } \\
(\%)\end{array}$ & $\begin{array}{c}\text { Proporção } \\
\text { do risco de } \\
\text { preço }(\%)\end{array}$ & $\begin{array}{l}\text { Diferença } \\
\text { absoluta }\end{array}$ & $\begin{array}{c}\text { Diferença } \\
\text { porcentual } \\
(\%)\end{array}$ & $\begin{array}{c}\text { Proporção } \\
\text { do risco de } \\
\text { preço (\%) }\end{array}$ \\
\hline $60 \%$ & $-0,04$ & $-55,24$ & $100 \%$ & $-0,10$ & $-23,60$ & $59 \%$ \\
\hline $65 \%$ & $-0,04$ & $-26,78$ & $99 \%$ & $-0,03$ & $-4,87$ & $59 \%$ \\
\hline $70 \%$ & $-0,02$ & $-5,02$ & $94 \%$ & 0,09 & 7,55 & $57 \%$ \\
\hline $75 \%$ & 0,04 & 6,79 & $89 \%$ & 0,32 & 18,45 & $55 \%$ \\
\hline $80 \%$ & 0,21 & 17,59 & $84 \%$ & 0,60 & 23,42 & $51 \%$ \\
\hline $85 \%$ & 0,42 & 20,99 & $76 \%$ & 0,93 & 25,66 & $47 \%$ \\
\hline $90 \%$ & 0,69 & 22,21 & $65 \%$ & 1,23 & 24,74 & $41 \%$ \\
\hline
\end{tabular}

Fonte: resultados da pesquisa

No modelo bivariado simulado, as correlações entre produtividade e preço, em Campo Mourão e Toledo, são baixas, sendo difícil visualizar o formato elipsoidal nos gráficos (a) e (b) da Figura 5. Entretanto, nota-se que as frequências no gráfico (a) são mais concentradas, de modo que o formato da distribuição tem características leptocúrticas. No gráfico (b), por outro lado, percebe-se uma maior distribuição das probabilidades, embora também não seja possível visualizar com clareza a tendência elipsoidal. 
(a) Densidade de Campo Mı

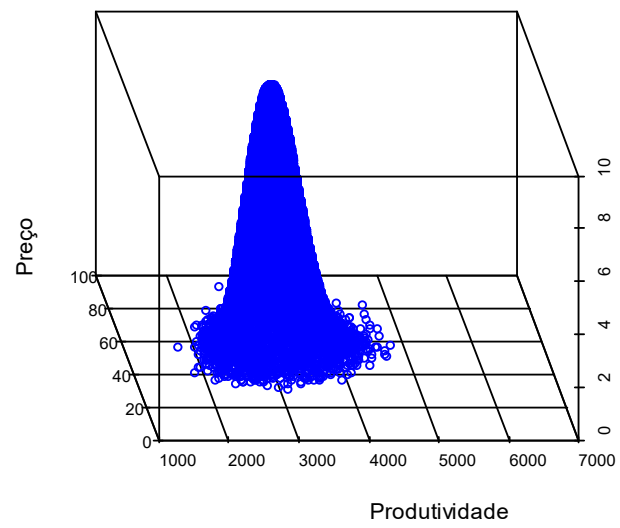

(b) Densidade de Toledo

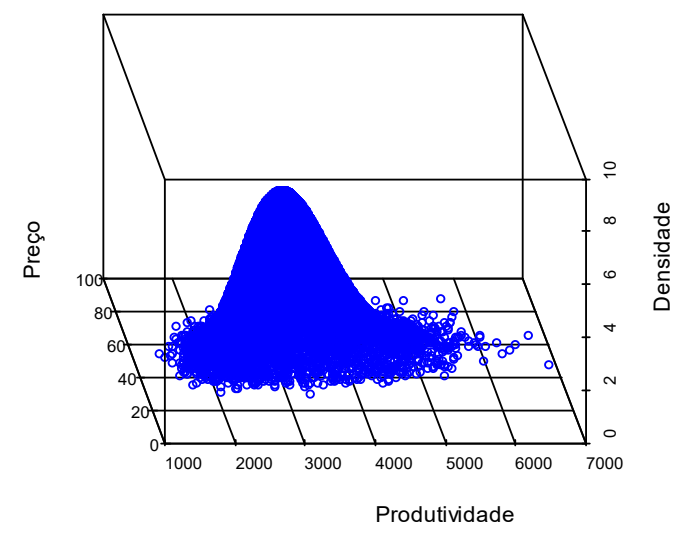

Figura 5. Produtividades, preços e densidades de Campo Mourão e Toledo. Fonte: resultados da pesquisa.

A comparação das taxas de prêmio do seguro de receita bruta pelas abordagens univariada e bivariada com as taxas do seguro de produtividade é ilustrada na Figura 6. Visualiza-se o que ocorre com as taxas na medida em que o nível de cobertura aumenta, sendo possível observar, como já discutido, que a taxa de seguro de receita é sempre mais elevada que a taxa de prêmio do seguro de produtividade.

(a) Comparativo das Taxas de C. Mourão

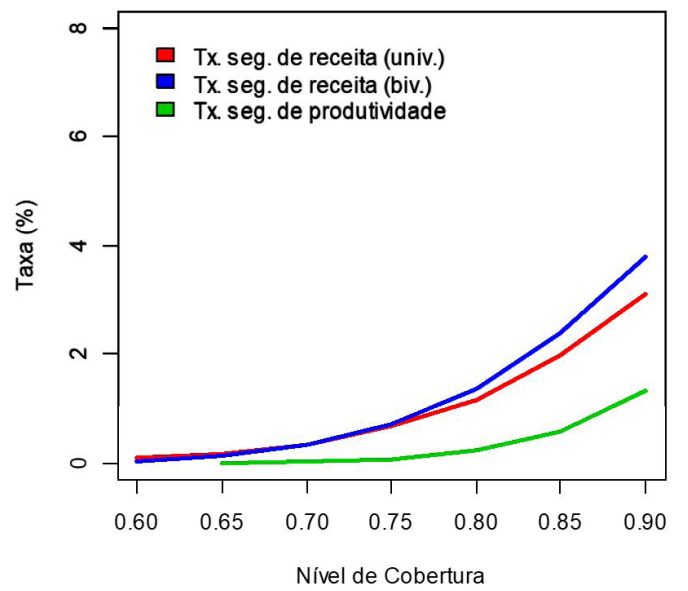

(b) Comparativo das Taxas de Toledo

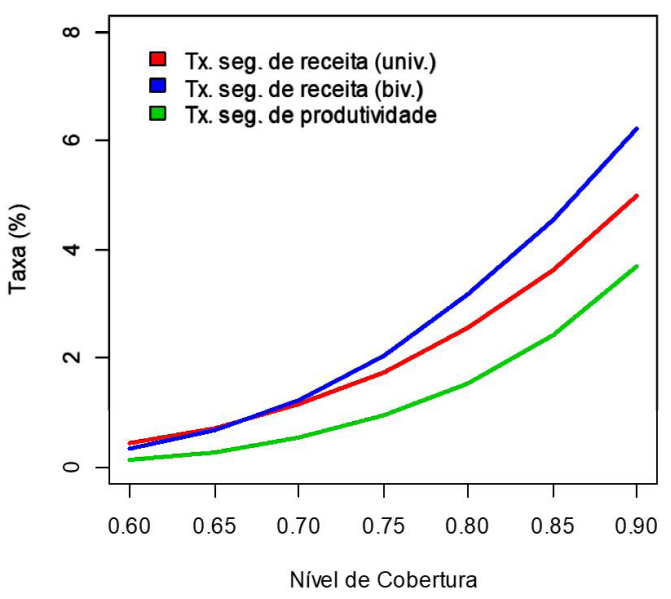

Figura 6. Comparativo das taxas de seguro de receita bruta univariada e bivariada e de produtividade, em diferentes níveis de cobertura, em Campo Mourão e Toledo. Fonte: resultados da pesquisa.

Percebe-se, pela análise da Figura 6, que a taxa de prêmio univariada é mais alta nos níveis de cobertura mais baixos, entre $60 \%$ e $70 \%$, e que a partir desses patamares a taxa do modelo bivariado torna-se mais elevada. O descolamento das taxas calculadas pelas abordagens univariada e bivariada é perceptível, pois a distância entre as duas linhas é crescente, tanto em Campo Mourão quanto em Toledo. 
A análise gráfica permite ainda identificar o preço como principal componente da taxa de prêmio do seguro de receita em Campo Mourão, tanto na abordagem univariada quanto na bivariada, embora neste último caso a participação do risco de preço seja ainda maior. No caso de Toledo, o principal componente da taxa é a produtividade, mas a participação do preço na taxa de prêmio do seguro de receita é maior quando se utilizou a abordagem bivariada.

\subsection{Modelagem da taxa de prêmio para determinadas margens sobre o custo de produção}

Outra proposta que vem sendo discutida no setor agropecuário diz respeito ao desenvolvimento de seguro de receita de modo a garantir margens sobre o custo de produção. Desse modo, o segurado optaria por uma margem fixada acima do custo de produção. Essa proposta atende à demanda dos produtores, pois visa garantir não só a cobertura do custo, como também parte do lucro cessante decorrente do sinistro.

Assim, apresentam-se a seguir taxas calculadas para níveis de garantia que representam a cobertura integral do custo total de produção de soja para Campo Mourão e Toledo, além de níveis incrementais de receita bruta de $10 \%$ a $60 \%$. O custo de produção utilizado, de $R \$$ 1.717,00 por hectare, foi extraído de Companhia Nacional de Abastecimento (2017), referente ao custo total de produção de soja para Campo Mourão, safra 2012/13, similar ao custo de Toledo. Tendo em vista que os resultados encontrados pelas abordagens univariada e bivariada não diferiram muito e que a correlação estimada entre as variáveis produtividade e preço foi inconsistente, optou-se por realizar as simulações apenas pela abordagem univariada.

Quadro 10. Taxas de prêmio puras para níveis distintos de cobertura do custo total de produção de soja para os municípios de Campo Mourão e Toledo.

\begin{tabular}{|c|c|c|c|}
\hline \multirow{2}{*}{$\begin{array}{c}\text { Porcentagem do } \\
\text { custo de produção }\end{array}$} & $\begin{array}{c}\text { Receita Garantida } \\
\text { (R\$/ha) }\end{array}$ & \multicolumn{2}{c|}{ Taxas de Prêmio } \\
\cline { 3 - 4 } & $1.717,00$ & 0,08 & Campo Mourão \\
\hline $100 \%$ & $1.888,70$ & 0,19 & 0,08 \\
\hline $110 \%$ & $2.060,40$ & 0,46 & 0,65 \\
\hline $120 \%$ & $2.232,10$ & 0,94 & 1,14 \\
\hline $130 \%$ & $2.403,80$ & 1,82 & 2,85 \\
\hline $140 \%$ & $2.575,50$ & 3,14 & 4,23 \\
\hline $150 \%$ & $2.747,20$ & 5,08 & 6,03 \\
\hline $160 \%$ & & & \\
\hline
\end{tabular}

Fonte: resultados da pesquisa

O nível correspondente a $100 \%$ do custo de produção equivale ao lucro zero, ou seja, ao valor do custo que cobre a integralidade dos custos variáveis e fixos, incluindo a remuneração da terra, do capital e do empresário. As simulações de $110 \%$ a $160 \%$ expõem as taxas que garantem níveis de cobertura acima do custo total, portanto, na área de lucro.

Conforme o Quadro 10, no nível de receita que cobre a integralidade dos custos de produção, as taxas calculadas foram de 0,08 para Campo Mourão e Toledo. As taxas calculadas aumentam gradualmente até o nível de $60 \%$ sobre o custo de produção, resultando em taxa de 5,08 e 6,03 para Campo Mourão e Toledo, respectivamente.

No caso da soja, que apresenta histórico de preços acima do custo de produção, os resultados não diferem muito dos apresentados anteriormente, exceto para níveis de cobertura acima de 
$50 \%$ do custo de produção. Contudo, para produtos agrícolas que apresentam comportamento de preços menos remuneradores, a fixação de margens acima do custo tende a determinar taxas mais elevadas, o que implica dificuldade de transferência do risco, devido à aversão de seguradoras e resseguradoras a subscrever o referido do risco.

\section{Conclusões}

Devido à relevância de se definir taxas de prêmio adequadas para o desenvolvimento do seguro de receita, o presente estudo concentrou-se em abordar metodologias que propiciem ampliar o conhecimento acerca do tema. Para o referido propósito, as abordagens univariada e bivariada foram adotadas, objetivando comparar os resultados, verificar as respectivas viabilidades de implantação e eventuais limitações.

A análise das distribuições das variáveis não permitiu que se rejeitasse a hipótese de normalidade, admitindo-se, assim, a utilização da distribuição normal para a representação das séries de produtividade dos municípios selecionados. Concluiu-se que suposição da normalidade na representação da produtividade é uma alternativa plausível para soja nos municípios analisados.

No caso dos preços da soja, também se observou a possibilidade de supor a normalidade das distribuições, considerando que os testes realizados não rejeitaram essa hipótese. Ademais, optou-se por utilizar os preços deflacionados, pois eles geraram estimativas consistentes e permitiram a comparação intertemporal das cotações.

Um resultado empírico que diferiu da teoria diz respeito à correlação linear entre a produtividade e o preço. Enquanto o pressuposto de correlação negativa entre essas variáveis é apontado como uma vantagem capaz de viabilizar o seguro de receita por meio da compensação dos riscos, foram estimados coeficientes de correlação positivos, implicando majoração dos riscos e não o contrário, conforme se esperava.

A correlação positiva encontrada pode ser creditada a uma série de fatores, mas uma investigação exaustiva ultrapassaria os objetivos deste estudo. Contudo, sugere-se para trabalhos acadêmicos futuros a análise dos seguintes fatores na dependência das variáveis preço e produtividade: câmbio; oferta e demanda mundial; estoques; preços dos produtos substitutos e complementares, dentre outros.

O estudo trouxe à luz uma opção de precificação dos riscos de duas variáveis aleatórias importantes no seguro de receita. A percepção da contribuição desses riscos não é importante apenas para a seguradora na definição dos níveis de cobertura, taxas e até mesmo o desenho dos produtos, mas também para os produtores que desejam otimizar suas estratégias de gestão de risco. Por outro lado, são limitações do estudo o reduzido número de municípios testados, cabendo aplicar a metodologia em maior escala. A ausência de bases de preços regionais também limita a precificação, pois obriga a utilização de indicadores que muitas vezes estão distantes das áreas de produção, descolando as taxas calculadas da realidade municipal.

Trabalhos futuros poderão utilizar diferentes séries de preços e investigar a correlação das produtividades em nível de propriedade rural e município, de modo a avaliar a adequação do coeficiente de variação (risco) utilizado na modelagem. Além disso, como as taxas puras não são comparáveis às taxas comerciais, sugere-se que estudos subsequentes se dediquem a estudar as taxas de carregamento do mercado, de modo a permitir a confrontação das taxas, a aderência do modelo e adequação das taxas praticadas pelo mercado segurador.

Taxas de prêmio para níveis de receita que garantam cobertura acima do custo de produção demonstraram-se viáveis para o caso da soja, devendo ser aprofundada, inclusive porque atende a importante reivindicação do setor. 
Para o desenvolvimento de produtos de seguro de receita, é importante construir bases de dados com informações regionais, sobretudo de preços, para permitir a análise das diferenças de base. Todavia, informações sobre a produtividade em nível de propriedade rural e condições meteorológicas também são carências que podem ser supridas por meio de um banco de dados dedicado à gestão do risco agrícola.

\section{Referências}

Adami, A., \& Ozaki, V. (2016). Estudo sobre a viabilidade do seguro receita: o caso da região oeste do Paraná. Revista de Economia e Sociologia Rural, 54, 305-318.

Arias, D., Mendes, P., \& Abel, P. (2015). Gestão de Riscos Agropecuários no Brasil: caminhos para uma visão integrada. Brasília: Banco Mundial.

Badcock, B., \& Hennessy, D. (1996). Input demand under yield and revenue insurance. American Journal of Agricultural Economics, 78, 416-427.

Bielza, M., Garrido, A., \& Sumpsi, J. (2004). Revenue insurance as an income stabilization policy: an application to the Spanish olive oil sector. Cahiers d'Économie et Sociologie Rurales, 70, 5-27.

Botts, R., \& Boles, J. (1958). Use of normal-curve theory in crop insurance ratemaking. Journal of Farm Economics, 40(3), 733-740.

Brasil. Ministério da Agricultura, Pecuária e Abastecimento - MAPA. (2020). Mapa negocia $R \$ 1,5$ bilhão para apoiar contratação do seguro rural em 2021. Recuperado em 18 de janeiro de 2020, de https://www.gov.br/agricultura/pt-br/assuntos/noticias/Mapa-negocia-R-1\%2C5\%20 bilhao-para-apoiar-contratacao-do-seguro-rural-em-2021

Centro de Estudos Avançado em Economia Aplicada - CEPEA. (2018). Séries de preços. Recuperada em 14 de outubro de 2018, de http://cepea.esalq.usp.br/soja

Coble, K., Heifner, R., \& Zuniga, M. (2000). Implications of crop yield and revenue insurance for producer hedging. Journal of Agricultural and Resource Economics, 25(2), 432-452.

Coble, K., Knight, T., Goodwin, B., Miller, M., \& Rejesus, R. (2010). A Comprehensive Review of the RMA APH and COMBO Rating Methodology. Recuperado em 15 de julho de 2011, de https://legacy.rma.usda.gov/pubs/2009/comprehensivereview.pdf

Companhia Nacional de Abastecimento - CONAB. (2017). Custos de produção. Recuperado em 15 de março de 2017, de https://www.conab.gov.br/info-agro/custos-de-producao

Fundação Getúlio Vargas - FGV. (2018). Indicadores de Preços: IGP-DI. Recuperado de em 15 de março de 2017, de https://extra-ibre.fgv.br/IBRE/sitefgvdados/default.aspx./

Goodwin, B., \& Ker, A. (1998). Nonparametric estimation of crop yield distributions: implications for rating group-risk crop insurance contracts. American Journal of Agricultural Economics, 80(1), 139-153.

Goodwin, B., \& Ker, A. (2002). Modeling price and yield risk. In R. Just \& R. Pope (Eds.), $A$ compreensive assessment of the role of risk in U.S. Agriculture (pp. 289-323). Norwell: Kluwer Academic Publishers.

Goodwin, B., \& Mahul, O. (2004). Risk modeling concepts relating to the design and rating of agricultural insurance contracts. Washington: The World Bank.

Goodwin, B., Roberts, M., \& Coble, K. (2000). Measurement of price risk in revenue insurance: implications of distributional assumptions. Journal of Agricultural and Resource Economics, 25(1), 195-214. 
Harri, A., Erdem, C., Coble, K., \& Knight, T. (2009). Crop Yield Distributions: a reconciliation of previous research and statistical tests for normality. Review of Agricultural Economics, 31(1), 163-182.

Hennessy, D., Badcock, B., \& Hayes, D. (1997). The budgetary and producer welfare effects of revenue assurance. American Journal of Agricultural Economics, 79(3), 1024-1034.

Hull, J. (2005). Fundamentos dos mercados futuros e de opções (597р.). São Paulo: Bolsa de Mercadorias \& Futuros.

Instituto Brasileiro de Geografia e Estatística - IBGE. (2018). Portal SIDRA. Recuperado em 15 de novembro de 2018, de http://www.sidra.ibge.gov.br/

Instituto Paranaense de Desenvolvimento Econômico e Social - IPARDES. Portal IPARDES. (2018). Recuperado em 14 de dezembro de 2018, de http://www.ipardes.pr.gov.br/imp/index.php

Johnson, M., \& Tenenbein, A. (1981). A bivariate distribution family with specified marginal. Journal of the American Statistical Association, 86, 198-201.

Johnson, R., \& Wichern, D. (2007). Applied multivariate statistical analysis (6th ed.) Upper Saddle River: Pearson Prentice Hall.

Just, R., \& Weninger, Q. (1999). Are crop yields normally distributed? American Journal of Agricultural Economics, 81(2), 287-304.

Ker, A., \& Goodwin, B. (2000). Nonparametric estimation of crop insurance rates revisited. American Journal of Agricultural Economics, 83, 463-478.

Lapan, H., \& Moschini, G. (1994). Hedging under price, basis, and production risk. American Journal of Agricultural Economics, 73(3), 465-477.

Lawas, C. (2005). Crop insurance premium rate impacts of flexible parametric yield distributions: an evaluation of the Johnson family of distributions (Master thesis). Texas: Texas Tech University. Recuperado em 14 de dezembro de 2018, de https://ttu-ir.tdl.org/bitstream/ handle/2346/1280/Lawas_thesis.pdf?sequence=1\&isAllowed=y

Micheleto, G. (2011). Contribuições para o desenvolvimento do seguro agrícola de renda para o Brasil: evidências teóricas e empíricas (Tese de doutorado). São Paulo: Universidade de São Paulo. Recuperado em 14 de dezembro de 2018, de https://www.teses.usp.br/teses/ disponiveis/11/11132/tde-12092011-163544/en.php

Nelson, C., \& Preckel, P. (1989). The conditional beta distribution as a stochastic production function. American Journal of Agricultural Economics, 71(2), 370-378.

Ozaki, V. (2005). Métodos atuariais aplicados à determinação da taxa de prêmio de contratos de seguro agrícola: um estudo de caso (Tese de doutorado). São Paulo: Universidade de São Paulo. Recuperado em 14 de dezembro de 2018, de https://teses.usp.br/teses/ disponiveis/11/11132/tde-11072005-160540/en.php

Ramirez, A., Manfredo, M., \& Sanders, D. (2005). Revenue insurance for Spanish wine grapes. Journal of International Agricultural Trade and Developments, 1(2), 149-168.

Tew, B., \& Reid, D. (1988). Probability distributions of crop prices, yields, and gross revenue. Northeastern Journal of Agricultural and Resource Economics, 7(3), 118-121.

Turvey, C. (1992). Contingent claim pricing models implied by agricultural stabilization and insurance policies. Canadian Journal of Agricultural Economics, 40, 183-198.

Umberto, C. (2011). Copulas in finance. In M. Lovric (Ed.), International Encyclopedia of Statistical Science. Berlin: Springer. 
Upadhyay, B., \& Smith, E. (2005). Modeling crop yield distributions from small samples. In Caes Annual Meeting. San Francisco: CAES. Recuperado em 10 abril de 2012, de https://core. ac.uk/download/pdf/6551155.pdf

Vedenov, D. (2008). Application of copulas to estimation of joint crop yield distributions. In American Agricultural Economics Association Annual Meeting. Orlando: American Agricultural Economics Association. Recuperado em 14 de maio de 2011, de http://ageconsearch.umn. edu/bitstream/6264/2/464004.pdf

Wolf, C., Black, R., \& Hadrich, J. (2009). Upper Midwest dairy farm revenue variation and insurance implications. Agricultural Finance Review, 69(3), 346-358. 